\title{
The Effect of Confucianism on Job Crafting Using Psychological Contract Fulfilment as the Mediating Variable and Distributive Justice as the Moderating Variable
}

\author{
Liping Liu (D), Chunyu Zhang (D) \\ School of Economics and Management, Guangxi Normal University, Guilin, Guangxi, People's Republic of China \\ Correspondence: Chunyu Zhang, School of Economics and Management, Guangxi Normal University, I5 Yucai Road, Qixing District, Guilin, Guangxi, \\ 541004, People’s Republic of China, Tel +86 13457660453, Fax +86773 58I6858, Email 468I60345@qq.com
}

\begin{abstract}
Purpose: Job crafting can improve employees' performance and competitive advantage. This study integrated the self-determination and equity theories to examine the relation between an individual's Confucianism and job crafting by highlighting the mediating effect of psychological contract fulfilment and the moderating effect of distributive justice on this relation.

Participants and Methods: Data were collected in two waves from 372 employees in numerous private companies in Guangxi, China.

Results: The hypothesized model was supported in part. Specifically, as expected, psychological contract fulfilment mediated the positive relation between Confucianism and task crafting and cognitive crafting. Confucianism had a positive effect on psychological contract fulfilment and relational crafting, while psychological contract fulfilment had no mediating effect and its positive effect on relational crafting was not significant. Distributive justice moderated the relation between psychological contract fulfilment and cognitive crafting and task crafting positively.

Conclusion: This study reveals the mechanism of Confucianism's effect on job crafting from a new perspective and confirms its differing effects on different types of job crafting. Business managers should give attention to Confucianism and maximize their organization's psychological contract fulfilment to improve employees' job crafting.
\end{abstract}

Keywords: sustainable development, Chinese traditional culture, high-quality development, corporate environmental responsibility

\section{Introduction}

Managers have always been concerned about the way to improve employees' enthusiasm, and job crafting is correlated significantly and positively with individual initiative. ${ }^{1}$ Job crafting is a bottom-up initiative of employee change, ${ }^{2-4}$ which is an alternative to the traditional top-down approach. ${ }^{5}$ It is primarily the employee's treatment of job cognitions, tasks, and relations. ${ }^{6}$

Many studies have introduced job crafting into Management, and have confirmed that it has considerable benefits for individual employees. For example, job crafting improves their social capital, job performance, ${ }^{6}$ and job engagement. ${ }^{7}$ Further, it is correlated positively with organizational citizenship behavior, self-coordinated goal setting, job satisfaction, and work motivation. ${ }^{8}$ Therefore, this study explores the way to improve sales staff's job crafting.

The influencing factors of job crafting are divided primarily into the individual level and organizational level. At the organizational level, perceived organizational support ${ }^{9}$ and leadership empowerment affect cognitive crafting positively. ${ }^{10}$ At the individual level, it is based upon a person's beliefs about his/her ability to complete tasks and achieve goals. ${ }^{11}$ Thus, autonomy and innovative self-efficacy affect job crafting positively, ${ }^{9}$ while there is a significant negative relation between cynicism and job crafting. ${ }^{1}$ Cynicism is an attitude that reflects employees' apathy or 
indifference to their work. ${ }^{12}$ The concept of Zhong Yong thinking is precisely the opposite. Wu, Lin ${ }^{13}$ studied three aspects of Zhong Yong thinking. First, this type of thinking emphasizes that individuals should think about problems from multiple perspectives when expressing their opinions and should integrate different opinions when they do so. Harmony indicates that individuals act in a congenial manner. ${ }^{14}$ Zhong Yong thinking is representative of Confucianism, ${ }^{15}$ which affects employees' behavioral intentions. ${ }^{16}$ Largely, Confucianism includes five aspects: values; benevolence; justice; courtesy; knowledge, and integrity. ${ }^{17}$ Some scholars have used benevolence, courtesy, loyalty, forgiveness, faithfulness, and righteousness to measure Confucianism as well, and tested its positive and significant effects on core transformational leader behavior and high-performance expectations through empirical research. ${ }^{18}$ Therefore, the way Confucianism affects job crafting is the main subject of this study.

Prior studies have found that work values have a positive effect through the psychological contract's mediating role and affect service-oriented organizational citizenship behavior positively. ${ }^{19}$ The psychological contract refers to employees' beliefs, expectations, and views related to the satisfaction of mutual obligations (implicit commitments) between employees and employers. ${ }^{20}$ Self-determination theory states that individuals make free choices in their own actions based upon a full understanding of their individual needs and environmental information. ${ }^{21}$ Therefore, this study explores the relation between Confucianism, psychological contract fulfilment, and job crafting based upon self-determination theory.

Prior research has demonstrated that distributive justice plays a mediating role in the relation between transformational leadership and knowledge sharing behavior, ${ }^{22}$ and has been shown to moderate the indirect effect of moral disengagement between differential leadership and organizational corruption negatively. ${ }^{23}$ According to equity theory, employees' work motivation is related not only to remuneration, but also to whether they believe the distribution of remuneration overall is fair or not. ${ }^{23}$ Hence, distributive justice is an individual's view of the fairness of resource allocation. ${ }^{24}$ Therefore, this study explores whether distributive justice enhances the relation between psychological contract fulfilment and job crafting.

Further, the study analyzes the psychological contract and distributive justice in Confucianism's effect on job crafting. It compensates not only for the deficiencies in previous theoretical research, but also expands the scope of research further on the basis of existing theories. This will help enterprise managers find better ways to improve employee job crafting, and will improve enterprises' sustainability. Finally, the research results have implications for their human resources and management practices.

The paper is constructed as follows. First, we review the literature on Confucianism, psychological contract fulfilment, job crafting, and distributive justice, and propose the research hypotheses. Second, we describe the research method and data collection processes. Third, we present the research results. Finally, we provide theoretical and practical implications.

\section{Literature Review}

\section{Self-Determination Theory}

Self-determination theory is used often to explain individual behaviors, such as environmental behavior, ${ }^{25}$ organizational citizenship behavior, ${ }^{26}$ and job engagement. ${ }^{27}$ The theory states that individuals choose their own actions freely based upon a full understanding of their individual needs and environmental information. ${ }^{21}$ The theory divides individual motivation into internal and external according to the degree of self-integration. The generation of different motivations is affected by individuals and the environment's comprehensive action. Internal motivation is based upon one's own interests and hobbies and can meet the actors' needs continuously. ${ }^{21}$ For example, employees behave in a particular way because their behaviors are of personal interest to them. ${ }^{28}$ External motivation refers to a behavioral tendency attributable to external forces that yield a specific result. ${ }^{21}$ For example, an employee may perform a behavior to meet job requirements. ${ }^{28}$ In addition, there are four types of codes of conduct for external motivation. ${ }^{29}$ From the least to the most autonomous, the external regulatory behavior controlled is as follows. To avoid the integrated regulatory behavior of guilt and shame, supervision with personal approval is recognized through identification, in which comprehensive supervision is consistent with the individual's values, goals and needs. ${ }^{30}$ Self-determination theory includes three basic 
psychological needs: autonomy; competence, and relevance. Different motivations are related closely to these three needs. When these needs are in a social context, for example, when culture, context, and inner psychology are supported and can be realized by individuals, prosocial behaviors will be strengthened, ${ }^{31}$ and job crafting will become a positive work behavior. ${ }^{32}$ Self-determination theory holds that these basic needs are essential, and if any are unmet, there will be obvious functional costs, because basic needs affect all aspects of human behavior. ${ }^{33}$

\section{Equity Theory}

Equity theory is used to explain employees' positive or negative behavior. According to the theory, employees judge whether an organization's decision is fair or not and then react. ${ }^{34}$ For example, when employees feel that they are treated unfairly, they will engage in various negative behaviors, such as loitering online. ${ }^{34}$ In contrast, when they feel that they are treated fairly, they will engage in certain positive behaviors, such as sharing information. ${ }^{35}$

\section{Confucianism and Job Crafting}

The core of Confucianism can be summarized in 6 Chinese characters, or in pinyin, "Ren", "Li", "Zhong", "Shu", "Xin", and "Yi". ${ }^{18}$ Benevolence (Ren) is the core structure of ethical thought. ${ }^{18}$ Confucius said, "I set my heart on the way, based myself on virtue, lean upon benevolence for support and take my recreation in the arts" (The Analects, VII/6). ${ }^{18}$ Decorum (Li) is the norm for people's daily behavior. ${ }^{14}$ Thus, the meaning of loyalty (Zhong) is akin to doing one's best, while magnimity (Shu) implies consideration and reciprocation of others' feelings. ${ }^{18}$ Trust (Xin) or promise is one of the core ideas of Confucianism. ${ }^{18}$ Finally, righteousness (Yi) is generally the converse of "profit" or "gain". ${ }^{18}$ Confucianism's influence is controversial. $\mathrm{Kim}^{36}$ indicated that Confucianism is related negatively to creativity, while other scholars hold different opinions. For example, Confucianism affects the quality of carbon information disclosure positively, ${ }^{37}$ is associated negatively with stock price crash risk, ${ }^{38}$ and reduces corporate irregularities significantly. ${ }^{39}$ Further, the Confucian ethic of filial piety has been found to be associated negatively with suicide among Chinese youths. ${ }^{40}$

Job crafting refers to employees' change from bottom to top in cognition, task, and relation. ${ }^{6}$ On the one hand, employees' negative attitude toward work is not conducive to their job crafting, and is correlated negatively with cynicism. ${ }^{12}$ On the other, individual initiative, proactive personality, job engagement, employability, job performance, ${ }^{1}$ organizational citizenship behavior, self-coordinated goal setting, job satisfaction, and work enthusiasm are correlated positively and significantly with job crafting. ${ }^{8}$ Although Confucianism does not include these factors explicitly, the ideas advocated by Confucianism are related to them more or less. For example, "Yi" includes responsibility and dedication in life, and work engagement also refers to dedication. ${ }^{41}$ Organizational citizenship behavior is behavior that is beneficial to the organization, ${ }^{42}$ which takes ethics as the benchmark. Similarly, "Ren" is also the criterion of virtue. ${ }^{43}$

This study proposes that employees with strong Confucian values are more inclined to job crafting. According to the self-determination theory, job crafting is employees' self-determined behavior, which is generated by internal motivation. Confucianism guides employees to have a positive attitude toward work. As a result, employees will see a change in their work attitude as they become more interested in their work.

Therefore, this study puts forward the following hypothesis:

H1: Confucianism affects job crafting — task crafting, cognitive crafting, and relational crafting — positively.

\section{Psychological Contract Fulfilment and Job Crafting}

Psychological contract fulfilment is an informal contract between an organization and its employees, ${ }^{19}$ and refers to an employee's personal belief in exchanging reciprocal agreements with the organization. ${ }^{44,45}$ Freese, Schalk, Croon ${ }^{46}$ combined belief and relation and concluded that the psychological contract is employees' belief in mutual obligation in their relation with the organization, which influences that relation and controls their behavior.

Psychological contract fulfilment is an important determinant of employees' attitudes and behavior. The principle of reciprocity indicates that an organization's failure to fulfil its commitments and obligations leads employees to be less likely to be engaged in their work. ${ }^{47}$ Psychological contract fulfilment has been found to be related positively to employees' perception of fairness and job satisfaction, and is related negatively to the intention to quit. ${ }^{48}$ Further, 
there are significant positive relations between psychological contract fulfilment, organizational citizenship behavior, and organizational performance. ${ }^{49}$ Hence, job crafting is among employees' most important positive behaviors. ${ }^{50}$ In addition, psychological contract fulfilment affects employees' innovative behavior via their engagement, ${ }^{51}$ which can influence job crafting positively and significantly. ${ }^{52}$

According to self-determination theory, employees' behavior is determined by external motivations. This study proposes that the enterprise's fulfilment of its commitments is conducive to its employees' positive behavior, such that employees change their cognition, relation, and task behavior actively for the enterprise to fulfil its commitments.

Therefore, we propose the following hypothesis:

H2: Psychological contract fulfilment affects job crafting — task crafting, cognitive crafting, and relational craftingpositively.

\section{Confucianism and Psychological Contract Fulfilment}

Confucianism is the basis of psychological contract fulfilment. Empirical studies of multinational corporations show that collectivist cultural values may influence psychological contracts through beliefs about the nature of social exchange. ${ }^{53}$ Work values influence employees' expectations of the organization through the content and frequency of information for which they search, such as career development opportunities. ${ }^{45}$

According to self-determination theory, the individual and environment's combined effects influence employee behavior. This study proposes that employees' Confucian beliefs guide their perception of the environment. For example, employees with a stronger belief in Confucianism are highly loyal to the organization, and their perception of its commitment is higher as well, in which case, employees will be more willing to take actions conducive to the organization's development.

Therefore, the following hypotheses are put forward:

H3: Confucianism affects psychological contract fulfilment positively.

H4: Confucianism influences job crafting — task crafting, cognitive crafting, relational crafting-through psychological contract fulfilment, which plays a mediating role.

\section{The Moderating Effect of Distributive Justice}

Previous studies have found that distributive justice moderates the relation between psychological contract consistency and affective and occupational commitment. This study proposes that employees' attachment should increase under conditions of high psychological contract congruence and high distributive justice because it indicates that the employer is not only willing, but able to reciprocate, and this should be done fairly. ${ }^{54}$ The relation between distributive justice and contract congruence is closer in low power distance than in high power distance cultures. $^{55}$

There is an implicit social contract between the organization and its employees, and the strength of an employee's social commitment to the organization depends upon whether the employee believes that the organization is fair or balanced in its rewards for its employees' organizational efforts and commitments. ${ }^{56}$ This study believes that when employees perceive high distributive justice, the enterprise can fulfil its commitment to employees well, and thus, they are more willing to make changes from the bottom up.

Therefore, the following hypothesis is proposed:

H5: Distributive justice moderates the relation between psychological contract fulfilment and job crafting-task crafting, cognitive crafting, and relational crafting-positively. The greater the distributive justice, the stronger psychological contract fulfilment's influence on job crafting-task crafting, cognitive crafting, and relational crafting. 


\section{Research Methods \\ Measures}

First, this study used Lin, Ho, and Lin's Confucianism Work Values Scale Lin, Ho, Lin, ${ }^{18}$ which has only one structure and six items. (1) "I never forget my goals even in the face of adversity"; (2) "I avoid offending others"; (3) "I think that harmony should be highly valued in the workplace, in other words, conflict should be avoided"; (4) "I am loyal to the organization"; (5) "I am always kind to my colleagues", and (6) "I will forgive others who make mistakes". Its Cronbach $\alpha$ is 0.825.

Second, the study used Niehoff and Moorman's Distributive Justice Scale Niehoff, Moorman. ${ }^{57}$ Although this scale is old, other scholars cite and use it often. The scale has just one dimension and five items, and investigates largely whether employees believe that their working hours, burdens, salaries, rewards, and responsibilities are fair. For example, "I feel my salary is reasonable". The scale's Cronbach $\alpha$ is 0.821 .

Third, Lee, Pillutla, and Law's Psychological Contract Fulfilment Scale was used in this study; it has only 3 items and examines primarily an organization's fulfilment of its commitments to employees. For example, "Overall, the organization has fulfilled its promise to me." Its Cronbach $\alpha$ is 0.758 .

Fourth, Slemp and Vella-Brodrick's Job Crafting Scale was used in this study Slemp, Vella-Brodrick, ${ }^{8}$ which is divided into 3 dimensions and has a total of 15 items. Task crafting has 5 items, which describes employees' introduction or change in their skills, interests, workloads, types related to the task. For example, "I will introduce new methods to improve my work". The scale's Cronbach $\alpha$ is 0.790 . The five cognitive crafting questions address the importance of the employees' work to the community, company, life purpose, life, and happiness. For example, "I think about how my work gives me purpose in life". The scale has a Cronbach $\alpha$ of 0.777 . The 5 questions that address relation crafting allow employees to get to know, make friends with, and mentor people at work, as well as participate in work-related or workplace social events. For example, "I try to get to know people at work." Its Cronbach $\alpha$ is 0.770 .

The questionnaire consists of five parts, the first four of which are formal questions. The questions on the scale previous scholars developed are answered on a 5-point Likert scale. The last section collects the respondents' sociodemographic information, including gender, age, education level, working position, salary, and years worked at the company. In addition, the original scale was written in English and was inconsistent with the respondents' language. After translating it into Chinese, a back-translation method was adopted to check the translation effect. ${ }^{58}$ Two authors performed the translation and back-translation independently.

\section{Sample and Procedure}

According to the "2019 China Vocational College Employment Report" MyCOS released, the employment rate of higher vocational college graduates in 2018 was $92 \%$, among which sales are the greatest occupation, with an employment rate of $8.9 \%$. According to the "2018 National Education Development Statistical Communique", in 2018, there were 3.6647 million graduates from regular colleges in China. This indicates that the addition of general college graduates in 2018 increased the number of salespeople by approximately 300,000. Therefore, sales staff is an important group that cannot be ignored.

The respondents were employees in numerous private companies in Guangxi, China. 800 questionnaires were distributed after obtaining the corporate executives' consent. To avoid common method variance, ${ }^{59}$ the questionnaires were collected at 2 time points. In the first wave, respondents were asked about Confucianism and distributive justice, and 612 questionnaires were collected. A week later, the second wave asked respondents about relation psychological contract fulfilment, job crafting, and demographics, and 403 questionnaires were collected. To check the respondents' attention level, three attention questions were asked about Confucianism, distributive justice, and psychological contract fulfilment, and respondents were asked to choose "strongly disagree", "disagree" and "generally". After 31 non-conforming questionnaires were deleted, 372 were valid, for an effective response rate of $61 \%$. The information of respondents as shown in Table 1.

\section{Common Method Variance (CMV)}

A variety of methods was used to test the CMV effect. First, Herman's one-factor test was conducted, and Factor analysis was performed in SPSS v. X. The results showed that more than one factor was extracted, and the maximum degree of 
Table I Demographic Data of Respondents

\begin{tabular}{|c|c|c|c|c|c|c|c|}
\hline \multicolumn{2}{|l|}{ Description } & \multirow{2}{*}{$\begin{array}{r}\text { Frequency } \\
69\end{array}$} & \multirow{2}{*}{$\begin{array}{l}\text { Percentage } \\
34.50 \%\end{array}$} & \multicolumn{2}{|c|}{ Description } & \multirow{2}{*}{$\begin{array}{r}\text { Frequency } \\
15\end{array}$} & \multirow{2}{*}{$\begin{array}{l}\text { Percentage } \\
7.50 \%\end{array}$} \\
\hline Gender & Male & & & Monthly & Less than 3000 & & \\
\hline & Female & $|3|$ & $65.50 \%$ & (RMB) & $300 I-6000$ & 86 & $43.00 \%$ \\
\hline \multirow[t]{5}{*}{ Age } & Under 24 years old & 22 & $11.00 \%$ & & $6001 \sim 9000$ & 60 & $30.00 \%$ \\
\hline & 25-34 years old & 126 & $63.00 \%$ & & $900 I-12,000$ & 28 & $14.00 \%$ \\
\hline & $35-44$ years old & 40 & $20.00 \%$ & & $|2,00|-15,000$ & 9 & $4.50 \%$ \\
\hline & 45-54 years old & 10 & $5.00 \%$ & & More than 15,001 & 2 & $1.00 \%$ \\
\hline & Over 55 years old & 2 & $1.00 \%$ & \multirow{5}{*}{$\begin{array}{l}\text { Working } \\
\text { years }\end{array}$} & Less than I year & 27 & $13.50 \%$ \\
\hline \multirow[t]{4}{*}{$\begin{array}{l}\text { The degree } \\
\text { of education }\end{array}$} & $\begin{array}{l}\text { Senior high School/below } \\
\text { technical secondary school }\end{array}$ & 17 & $8.50 \%$ & & $\begin{array}{l}\text { More than I year but } \\
\text { less than } 2 \text { years }\end{array}$ & 51 & $25.50 \%$ \\
\hline & College degree & 57 & $28.50 \%$ & & $\begin{array}{l}\text { More than } 2 \text { years but } \\
\text { less than } 5 \text { years }\end{array}$ & 72 & $36.00 \%$ \\
\hline & Bachelor's degree & 101 & $50.50 \%$ & & $\begin{array}{l}\text { More than } 5 \text { years but } \\
\text { less than } 10 \text { years }\end{array}$ & 34 & $17.00 \%$ \\
\hline & Graduate education & 25 & $12.50 \%$ & & More than 10 years & 16 & $8.00 \%$ \\
\hline \multirow{4}{*}{$\begin{array}{l}\text { Operating } \\
\text { post }\end{array}$} & General staff & 83 & $41.50 \%$ & & & & \\
\hline & Grassroots managers & 78 & $39.00 \%$ & & & & \\
\hline & Middle managers & 37 & $18.50 \%$ & & & & \\
\hline & Top management & 2 & $1.00 \%$ & & & & \\
\hline
\end{tabular}

factor explanation was $34.39 \%(<50 \%) .{ }^{60}$ Second, the original model and the single factor model were constructed in AMOS v. 23. As shown in Table 2, the Chi-squared difference between the two models was significant. Both results indicate that no serious CMV exists. ${ }^{61}$

\section{Results}

\section{Model Fitting and Convergence Validity}

Confirmatory factor analysis (CFA) was performed in AMOS to test the models' fit, and the results are shown in Table 3. The indicators of the six-factor model were clearly better than those of the alternative models.

Convergent validity was tested by composite reliability (CR) and the average variance extracted (AVE). As shown in Table 4, all items' factor loadings exceeded $0.6,{ }^{62}$ and each variable's CR value was higher than $0.8 .{ }^{62,63}$ The AVE of all variable scores was greater than $0.5 .{ }^{63}$ In summary, all variables in the study demonstrated convergent validity.

Table 2 CFA Comparison Method for CMV

\begin{tabular}{|l|l|l|l|l|l|}
\hline & CMIN & DF & $\Delta$ CMIN & $\Delta$ DF & P \\
\hline Six-factor model & 798.971 & 362 & 730.802 & 15 & 0.000 \\
Single-factor model & 1529.773 & 377 & & & \\
\hline
\end{tabular}


Table 3 Model Fit

\begin{tabular}{|l|l|l|l|l|l|l|l|}
\hline & CMIN/DF & GFI & AGFI & IFI & CFI & RMSEA & SRMR \\
\hline Six-factor model & 2.207 & 0.870 & 0.843 & 0.900 & 0.899 & 0.057 & 0.0484 \\
\hline Four-factor model (CM, DJ, PC, TC+CC+RC) & 2.519 & 0.845 & 0.819 & 0.870 & 0.869 & 0.064 & 0.0534 \\
\hline Two-factor model (CM+PC, DJ+TC+CC+RC) & 3.577 & 0.766 & 0.729 & 0.777 & 0.776 & 0.083 & 0.0704 \\
\hline Single-factor model & 4.058 & 0.737 & 0.696 & 0.735 & 0.773 & 0.091 & 0.0748 \\
\hline
\end{tabular}

Abbreviations: CM, Confucianism; PC, psychological contract fulfilment; DJ, distributive justice; TC, task crafting; CC, cognitive crafting; RC, relational crafting.

Table 4 Factor Loading and Convergent Validity

\begin{tabular}{|c|c|c|c|c|c|c|c|c|c|}
\hline Variables & Order & $\begin{array}{l}\text { Loading } \\
\text { Factor }\end{array}$ & CR & AVE & Variables & Order & $\begin{array}{l}\text { Loading } \\
\text { Factor }\end{array}$ & CR & AVE \\
\hline \multirow[t]{6}{*}{ Confucianism } & QI & 0.619 & \multirow[t]{6}{*}{0.873} & \multirow[t]{6}{*}{0.534} & \multirow[t]{5}{*}{ Task crafting } & Q15 & 0.730 & \multirow[t]{5}{*}{0.856} & \multirow[t]{5}{*}{0.543} \\
\hline & Q2 & 0.661 & & & & Q16 & 0.655 & & \\
\hline & Q3 & 0.694 & & & & Q17 & 0.649 & & \\
\hline & Q4 & 0.702 & & & & Q18 & 0.614 & & \\
\hline & Q5 & 0.695 & & & & Q19 & 0.650 & & \\
\hline & Q6 & 0.607 & & & \multirow{5}{*}{$\begin{array}{l}\text { Cognitive } \\
\text { crafting }\end{array}$} & Q20 & 0.608 & \multirow[t]{5}{*}{0.848} & \multirow[t]{5}{*}{0.528} \\
\hline \multirow{3}{*}{$\begin{array}{l}\text { Psychological contract } \\
\text { fulfilment }\end{array}$} & Q7 & 0.738 & \multirow[t]{3}{*}{$0.86 \mathrm{I}$} & \multirow[t]{3}{*}{0.674} & & Q21 & 0.709 & & \\
\hline & Q8 & 0.684 & & & & Q22 & 0.681 & & \\
\hline & Q9 & 0.746 & & & & Q23 & 0.614 & & \\
\hline \multirow[t]{6}{*}{ Distributive justice } & Q10 & 0.765 & \multirow[t]{5}{*}{0.875} & \multirow[t]{5}{*}{0.583} & & Q24 & 0.602 & & \\
\hline & QII & 0.666 & & & \multirow{5}{*}{$\begin{array}{l}\text { Relational } \\
\text { crafting }\end{array}$} & Q25 & 0.639 & \multirow[t]{5}{*}{0.844} & \multirow[t]{5}{*}{0.521} \\
\hline & Q12 & 0.687 & & & & Q26 & 0.604 & & \\
\hline & Q13 & 0.631 & & & & Q27 & 0.680 & & \\
\hline & Q14 & 0.726 & & & & Q28 & 0.616 & & \\
\hline & & & & & & Q29 & 0.628 & & \\
\hline
\end{tabular}

\section{Correlation and Discriminant Validity}

Correlation analysis was performed with SPSS, as shown in Table 5. There was a positive correlation between variables and variables. The diagonal is the square root of AVE, which was greater than the correlation coefficient of the row and column and indicated that the variables have discriminant validity.

\section{Hypothesis Tests}

A structural equation model was constructed in SmartPLS to test the hypotheses, as shown in Table 6 and Figure 1, and the Bootstrap subsample was set to $2000{ }^{64}$ The method used to calculate the moderating effect was set as two-stage, and product term generation was standardized.

First, the adjusted $\mathrm{R}^{2}$ of the psychological contract fulfilment was 0.275 , which indicated that the model explained $27.5 \%$ of psychological contract fulfilment. Further, the adjusted $\mathrm{R}^{2}$ of cognitive crafting, relational crafting, and task 
Table 5 Correlation and Discriminant Validity

\begin{tabular}{|l|l|l|l|l|l|l|}
\hline & Confucianism & $\begin{array}{l}\text { Distributive } \\
\text { Justice }\end{array}$ & $\begin{array}{l}\text { Psychological Contract } \\
\text { Fulfilment }\end{array}$ & $\begin{array}{l}\text { Task } \\
\text { Crafting }\end{array}$ & $\begin{array}{l}\text { Cognitive } \\
\text { Crafting }\end{array}$ & $\begin{array}{l}\text { Relational } \\
\text { Crafting }\end{array}$ \\
\hline Confucianism & 0.731 & & & & & \\
\hline Distributive justice & $0.492^{* *}$ & 0.763 & & & & \\
\hline $\begin{array}{l}\text { Psychological contract } \\
\text { fulfilment }\end{array}$ & $0.527^{* *}$ & $0.670^{* *}$ & 0.821 & & & \\
\hline Task crafting & $0.422^{* *}$ & $0.479^{* *}$ & $0.493^{* *}$ & 0.737 & & \\
\hline Cognitive crafting & $0.516^{* *}$ & $0.555^{* *}$ & $0.510^{* *}$ & $0.682^{* *}$ & 0.727 & $0.683^{* *}$ \\
\hline Relational crafting & $0.514^{* *}$ & $0.554^{* *}$ & $0.479 * *$ & $0.536^{* *}$ & 0.722 \\
\hline
\end{tabular}

Notes: **At the $0.0 \mathrm{I}$ level (two-tailed), the correlation is significant. The diagonal is the square root of AVE.

Table 6 Summary of Hypothesis

\begin{tabular}{|c|c|c|c|c|c|c|c|}
\hline \multirow{3}{*}{$\begin{array}{l}\text { Path } \\
\text { Direct effect }\end{array}$} & \multirow[b]{3}{*}{ Beta } & \multirow[b]{3}{*}{$p$-value } & \multicolumn{4}{|c|}{ 95\% Confidence Interval } & \multirow[t]{3}{*}{ VIF } \\
\hline & & & \multicolumn{2}{|l|}{ PC } & \multicolumn{2}{|l|}{ BC } & \\
\hline & & & $2.50 \%$ & $97.50 \%$ & $2.50 \%$ & $97.50 \%$ & \\
\hline Confucianism -> Task crafting & 0.165 & 0.006 & 0.053 & 0.289 & 0.050 & 0.284 & 1.474 \\
\hline Confucianism -> Cognitive crafting & 0.270 & 0.000 & 0.162 & 0.383 & 0.152 & 0.374 & 1.474 \\
\hline Confucianism -> Relational crafting & 0.289 & 0.000 & 0.176 & 0.414 & 0.169 & 0.405 & 1.474 \\
\hline Psychological contract fulfilment -> Task crafting & 0.272 & 0.000 & 0.117 & 0.408 & 0.126 & 0.411 & 2.045 \\
\hline Psychological contract fulfilment $->$ Cognitive crafting & 0.170 & 0.014 & 0.031 & 0.303 & 0.040 & 0.312 & 2.045 \\
\hline Psychological contract fulfilment -> Relational crafting & 0.099 & 0.183 & -0.062 & 0.229 & -0.042 & 0.247 & 2.045 \\
\hline Confucianism -> Psychological contract fulfilment & 0.527 & 0.000 & 0.420 & 0.634 & 0.391 & 0.621 & 1.000 \\
\hline Distributive justice -> Task crafting & 0.219 & 0.001 & 0.096 & 0.344 & 0.087 & 0.340 & 1.908 \\
\hline Distributive justice -> Cognitive crafting & 0.311 & 0.000 & 0.193 & 0.435 & 0.186 & 0.426 & 1.908 \\
\hline Distributive justice -> Relational crafting & 0.347 & 0.000 & 0.231 & 0.483 & 0.210 & 0.463 & 1.908 \\
\hline \multicolumn{8}{|l|}{ Moderating effect } \\
\hline Psychological contract fulfilment * Distributive justice -> Task crafting & 0.094 & 0.023 & 0.008 & 0.168 & 0.009 & 0.168 & 1.029 \\
\hline Psychological contract fulfilment * Distributive justice -> Cognitive crafting & 0.069 & 0.037 & 0.000 & 0.129 & 0.000 & 0.129 & 1.029 \\
\hline Psychological contract fulfilment * Distributive justice -> Relational crafting & 0.036 & 0.395 & -0.057 & 0.109 & -0.052 & 0.112 & 1.029 \\
\hline \multicolumn{8}{|l|}{ Indirect effect } \\
\hline Confucianism -> Psychological contract fulfilment -> Task crafting & 0.143 & 0.000 & 0.064 & 0.214 & 0.069 & 0.220 & \\
\hline Confucianism -> Psychological contract fulfilment -> cognitive crafting & 0.089 & 0.014 & 0.017 & 0.159 & 0.023 & 0.167 & \\
\hline Confucianism -> Psychological contract fulfilment -> Relational crafting & 0.052 & 0.181 & -0.033 & 0.119 & -0.021 & 0.133 & \\
\hline \multicolumn{8}{|l|}{ Total effect } \\
\hline Confucianism -> Task crafting & 0.308 & 0.000 & 0.195 & 0.416 & 0.193 & 0.413 & \\
\hline Confucianism -> Cognitive crafting & 0.359 & 0.000 & 0.251 & 0.460 & 0.245 & 0.454 & \\
\hline Confucianism -> Relational crafting & 0.341 & 0.000 & 0.229 & 0.443 & 0.234 & 0.446 & \\
\hline
\end{tabular}




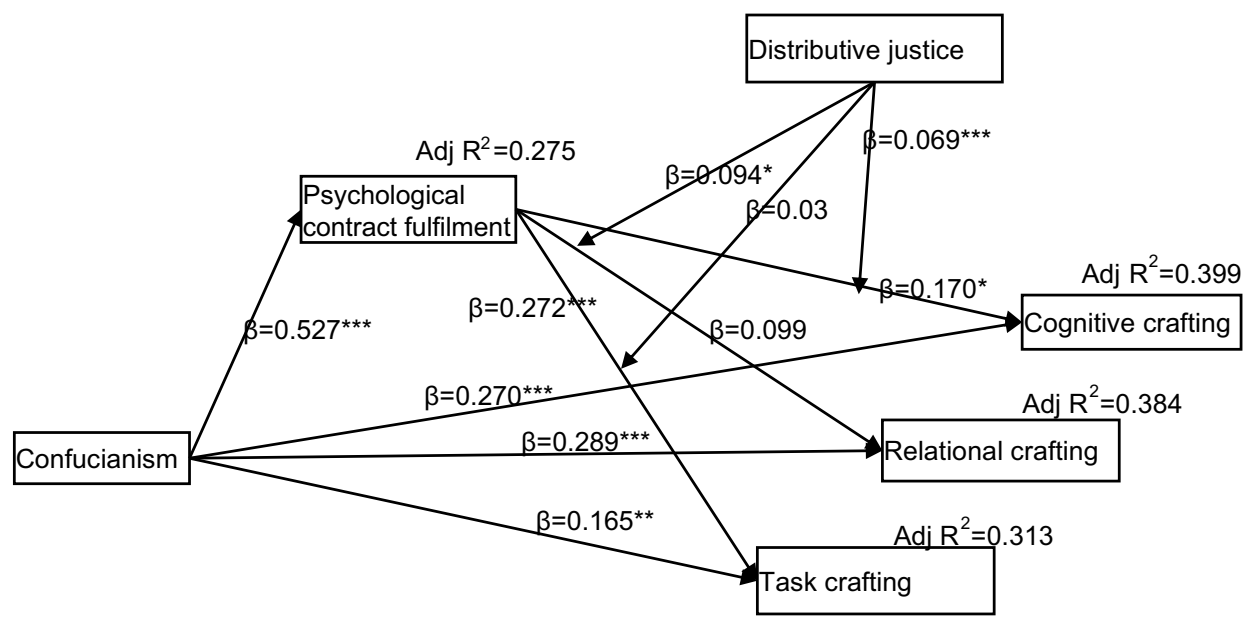

Figure I Research framework.

Notes: $* p<0.05$; $* * p<0.01 ; * * * p<0.001$.

crafting were $0.399,0.384$, and 0.313 , respectively, which indicates that the model explained $39.9 \%$ of cognitive crafting, $38.4 \%$ of relational crafting, and $31.3 \%$ of task crafting.

Second, Confucianism had a positive and significant effect on task crafting, cognitive crafting, and relational crafting, respectively, $(\beta=0.165, p<0.01 ; \beta=0.270, p<0.001 ; \beta=0.289, p<0.001)$. Hence, Hypotheses 1a, $1 \mathrm{~b}$, and 1c were supported. Psychological contract fulfilment affected task crafting $(\beta=0.272, p<0.001)$ and cognitive crafting $(\beta=0.170$, $p<0.05)$ positively and significantly. Hence, Hypotheses $2 \mathrm{a}$ and $2 \mathrm{~b}$ were supported. However, psychological contract fulfilment's negative effect on relational crafting was not significant $(\beta=0.099, p=0.183)$. Therefore, Hypothesis $2 \mathrm{c}$ was not supported. Confucianism affected psychological contract fulfilment positively and significantly $(\beta=0.527, p<0.001)$, and hence, Hypothesis 3 was supported. Further, Confucianism affected task crafting through psychological contract fulfilment positively and significantly $(\beta=0.143, p<0.001)$, which demonstrated that psychological contract fulfilment had a mediating effect. Confucianism affected cognitive crafting through psychological contract fulfilment positively and significantly $(\beta=0.089, p<0.05$ ), which indicated that psychological contract fulfilment had a mediating effect. Therefore, Hypotheses $4 \mathrm{a}$ and $4 \mathrm{~b}$ were supported. However, Confucianism's negative effect on relational crafting through psychological contract fulfilment was not significant $(\beta=0.052, p=0.181)$, which indicates that psychological contract fulfilment had no mediating effect. Hence, Hypothesis $4 \mathrm{c}$ was not supported.

Third, distributive justice moderated psychological contract fulfilment's effect on task crafting ( $\beta=0.094, p<0.05$ ) and cognitive crafting $(\beta=0.069, p<0.05)$, respectively, positively. Hence, Hypotheses $5 \mathrm{a}$ and $5 \mathrm{~b}$ were supported. However, distributive justice did not moderate psychological contract fulfilment's effect on relational crafting $(\beta=0.036$, $p=0.395)$ positively or significantly. Hence, Hypothesis $5 \mathrm{c}$ was not supported.

\section{Discussion and Conclusion}

\section{Theoretical Implications}

This research makes three primary contributions. First, our study explains Confucianism's effect on job crafting based upon the self-determination and equity theories. This departs from previous studies on job crafting that have adopted the broaden-and-build theory primarily to elucidate the organization-related antecedents of job crafting, eg, Rogala, Cieslak. ${ }^{65}$ Similarly, our research is among the first to identify an individual-related antecedent's (Confucianism) positive effect on job crafting. Indeed, as a key cultural value rooted in traditional Chinese society, Confucianism still has a lingering influence on employees' attitudinal and behavioral outcomes in contemporary workplaces. ${ }^{14}$ Our research findings contribute to this literature and indicate that Confucianism serves as a micro-foundation for employee sustainability that enhances their job crafting. 
Second, while few studies have investigated the mediating mechanisms between Confucianism and job crafting, this study demonstrated that psychological contract fulfilment mediates the relations between Confucianism and task, job, and cognitive crafting. Our study showed that Confucianism facilitates task and cognitive crafting by improving employees' perception of psychological contract fulfilment. This finding lends support to the prevalent belief that Zhong Yong thinking (Confucianism) enhances employees' survivability. ${ }^{14}$ Job crafting in this research includes three distinct, but interrelated components: task crafting; cognitive crafting, and relational crafting. We found that the greater the psychological contract fulfilment, the greater the task crafting and cognitive crafting. As such, our result echoes previous research that has shown that psychological contract fulfilment affects employees' innovative behaviour through employee engagement, ${ }^{51}$ while employee engagement influences job crafting positively and significantly. ${ }^{52}$ Further, we revealed that the path "Confucianism $\rightarrow$ psychological contract fulfilment $\rightarrow$ relational crafting" is not significant. A plausible interpretation of this outcome is that the association between Confucianism and relational crafting may be direct, and yet not activate employees' perception of psychological contract fulfilment. This is consistent with prior research that has shown that gratitude can influence job crafting both directly and indirectly. ${ }^{32}$

Third, we developed a moderation model in which distributive justice moderated the relations between psychological contract fulfilment and task and cognitive crafting.

Confucianism had positive effects on psychological contract fulfilment, task crafting, cognitive crafting, and relational crafting, while it demonstrated a mediating effect between Confucianism and task crafting and cognitive crafting, but did not mediate the effect between Confucianism and relational crafting. This indicates that the greater the employee's level of understanding of Confucianism, the greater the psychological contract fulfilment, task crafting, cognitive crafting, and relational crafting. Psychological contract fulfilment had a positive effect on task crafting and cognitive crafting, while it had no significant effect on relational crafting. A possible reason for this is that the extent to which the company fulfils its commitments to employees does not change their ability to become acquainted with, make friends with, and mentor people at work, as well as participate in social activities related to work or held in the workplace. Distributive justice moderated the relation between psychological contract fulfilment and task and cognitive crafting positively, but did not moderate the relation between psychological contract fulfilment and relational crafting. A potential reason for this result is that regardless of the employees' perception of distributive justice, the effect of psychological contract fulfilment on relational crafting cannot be changed.

\section{Practical Implications}

Current research has confirmed that Confucianism has a positive effect on job crafting. The Confucian principles of benevolence, courtesy, loyalty, forgiveness, trustworthiness, and righteousness encourage individuals to change their tasks, cognitions, and relations from the bottom up. Therefore, business managers should consider hiring people with strong Confucian values and beliefs when they recruit new salespersons. Second, current research has demonstrated that Confucianism affects task and cognitive crafting via psychological contract fulfilment, a factor that cannot be ignored. Although individual's Confucianism improves their evaluation of their organization's degree of fulfilment of its promises, organizations themselves should lead by example and improve the degree to which they do so. Then, their employees will change their tasks and cognitions from the bottom up. Third, distributive justice moderated the relation between psychological contract fulfilment and task crafting and cognitive crafting positively. Therefore, the greater the distributive justice, the greater the Confucianism, and the greater the task and cognitive crafting. Organization managers should also be aware of the importance of distributive justice. Therefore, they should pay attention to the fairness of employees' working hours, workload, wages, rewards, and responsibilities.

\section{Research Limitations and Recommendations}

We acknowledge that this research has several limitations of. First, the results revealed that the Beta values of the paths, distributive justice moderates the effect of psychological contract fulfilment on task crafting, and distributive justice moderates the effect of psychological contract fulfilment on cognitive crafting were very low, and distributive justice had no significant moderating effect on psychological contract fulfilment in relational crafting. Hence, there are other factors that moderate the relation between psychological contract fulfilment and job crafting that need to be studied further. 
Second, all variables in this study used existing scales, but quantitative research on Confucianism is still not very mature compared with other fields, so future research should develop the Confucianism scales further. Third, Chinese culture is extensive and profound and follow-up studies can adopt other philosophical approaches and ideas, such as Mohism or Buddhism.

\section{Data Sharing Statement}

Data and other materials related to this research will be provided to qualified researchers on request.

\section{Ethics Statement}

This study was conducted in accordance with the Declaration of Helsinki, and Guangxi Normal University reviewed and approved the study protocol. All participants read and signed a consent form before they participated in the study.

\section{Disclosure}

The authors report no conflicts of interest in this work.

\section{References}

1. Tims M, Bakker AB, Derks D. Development and validation of the job crafting scale. J Vocat Behav. 2012;80(1):173-186. doi:10.1016/j. jvb.2011.05.009

2. Niessen C, Weseler D, Kostova P. When and why do individuals craft their jobs? The role of individual motivation and work characteristics for job crafting. Human Relations. 2016;69(6):1287-1313. doi:10.1177/0018726715610642

3. Bakker AB, Tims M, Derks D. Proactive personality and job performance: the role of job crafting and work engagement. Human Relations. 2012;65(10):1359-1378. doi:10.1177/0018726712453471

4. Wrzesniewski A, Dutton JE. Crafting a job: revisioning employees as active crafters of their work. Acad Manag Rev. 2001;26(2):179-201. doi: $10.2307 / 259118$

5. Gordon HJ, Demerouti E, Le Blanc PM, Bakker AB, Bipp T, Verhagen MA. Individual job redesign: job crafting interventions in healthcare. J Vocat Behav. 2018;104:98-114. doi:10.1016/j.jvb.2017.07.002

6. Zhang C, Liu L. The effect of job crafting to job performance. Knowl Manag Res Pract. 2021;19(2):253-262. doi:10.1080/14778238.2020.1762517

7. Tims M, Bakker AB, Derks D, Van Rhenen W. Job crafting at the team and individual level: implications for work engagement and performance. Group Organ Manag. 2013;38(4):427-454. doi:10.1177/1059601113492421

8. Slemp GR, Vella-Brodrick DA. The job crafting questionnaire: a new scale to measure the extent to which employees engage in job crafting. Int $J$ Wellbeing. 2013;3(2):126-146.

9. Kim H, Im J, Qu H. Exploring antecedents and consequences of job crafting. Int J Hosp Manag. 2018;75:18-26. doi:10.1016/j.ijhm.2018.02.014

10. Kim M, Beehr TA. Can empowering leaders affect subordinates' well-being and careers because they encourage subordinates' job crafting behaviors? J Leadersh Organ Stud. 2018;25(2):184-196. doi:10.1177/1548051817727702

11. Mäkikangas A, Bakker AB, Schaufeli WB. Antecedents of daily team job crafting. Eur J Work Organ Psychol. 2017;26(3):421-433. doi:10.1080/ 1359432X.2017.1289920

12. Schaufeli WB, Bakker AB. Job demands, job resources, and their relationship with burnout and engagement: a multi-sample study. J Organ Behav. 2004;25(3):293-315. doi:10.1002/job.248

13. Wu C-H, Lin Y-C. Development of a Zhong-yong thinking style scale. Indi Psychol Res Chin Soc. 2005;24:247-300.

14. Zhang C, Chen C. The effect of Zhong-yong thinking to employee survival ability: taking Chinese employees as an example. Int J Sociol Soc Policy. 2020;40(11/12):1319-1336. doi:10.1108/IJSSP-02-2020-0038

15. Zhang C, Fang -C-C. The effect of Chinese traditional culture on employee green behavior: literature review. Int J Human Resource Stud. 2020;10 (1):260-275. doi:10.5296/ijhrs.v10i1.16189

16. Chen C, Li X. Effects of Singles' day atmosphere stimuli and Confucian values on consumer purchase intention. Asia Pac J Market Logist. 2020;32 (7):1387-1405. doi:10.1108/APJML-05-2019-0294

17. Tsai H-T, Tsai C-L. The influence of the five cardinal values of Confucianism on firm performance. Rev Manag Sci. 2021;1-30. doi:10.1007/ s11846-021-00452-1.

18. Lin L-H, Ho Y-L, Lin W-HE. Confucian and Taoist work values: an exploratory study of the Chinese transformational leadership behavior. $J$ Bus Ethics. 2013;113(1):91-103. doi:10.1007/s10551-012-1284-8

19. Chen C-H, Kao RH. Work values and service-oriented organizational citizenship behaviors: the mediation of psychological contract and professional commitment: a case of students in Taiwan Police College. Soc Indic Res. 2012;107(1):149-169. doi:10.1007/s11205-011-9832-7

20. Birtch TA, Chiang FF, Van Esch E. A social exchange theory framework for understanding the job characteristics-job outcomes relationship: the mediating role of psychological contract fulfillment. Int J Human Resource Manag. 2016;27(11):1217-1236. doi:10.1080/09585192.2015.1069752

21. Ryan RM, Deci EL. Self-determination theory and the facilitation of intrinsic motivation, social development, and well-being. Am Psychol. 2000;55 (1):68-78. doi:10.1037/0003-066X.55.1.68

22. Le PB, Lei H. How transformational leadership supports knowledge sharing: evidence from Chinese manufacturing and service firms. Chin Manag Stud. 2017;11(3):479-497. doi:10.1108/CMS-02-2017-0039

23. Tang Y, Zhan X, Chen K. Differential leadership and organizational corruption in China: mediating role of moral disengagement and moderating role of organizational justice. Chin Manag Stud. 2018;12(4):795-811. doi:10.1108/CMS-12-2017-0344 
24. Ohana M, Meyer M. Distributive justice and affective commitment in nonprofit organizations. Employee Relations. 2016;38(6):841-858. doi:10.1108/ER-10-2015-0197

25. Gilal FG, Chandani K, Gilal RG, Gilal NG, Gilal WG, Channa NA. Towards a new model for green consumer behaviour: a self-determination theory perspective. Sustain Dev. 2020;28(4):711-722. doi:10.1002/sd.2021

26. Umrani WA, Siyal IA, Ahmed U, Ali Arain G, Sayed H, Umrani S. Does family come first? Family motivation-individual's OCB assessment via self-efficacy. Person Rev. 2019;49(6):1287-1308. doi:10.1108/PR-01-2019-0031

27. Matsuo M. Effect of learning goal orientation on work engagement through job crafting. Person Rev. 2019;48(1):220-233. doi:10.1108/PR-112017-0346

28. Graves LM, Sarkis J, Zhu Q. How transformational leadership and employee motivation combine to predict employee proenvironmental behaviors in China. J Environ Psychol. 2013;35:81-91. doi:10.1016/j.jenvp.2013.05.002

29. Deci E, Ryan R. Intrinsic Motivation and Self-Determination in Human Behavior. New York, NY: Springer; 1985.

30. Webb D, Soutar GN, Mazzarol T, Saldaris P. Self-determination theory and consumer behavioural change: evidence from a household energy-saving behaviour study. J Environ Psychol. 2013;35:59-66. doi:10.1016/j.jenvp.2013.04.003

31. Deci EL, Ryan RM. Self-determination theory: a macrotheory of human motivation, development, and health. Can Psychol. 2008;49(3):182. doi:10.1037/a0012801

32. Chen H, Yang X, Xia W, Li Y, Deng Y, Fan C. The relationship between gratitude and job satisfaction: the mediating roles of social support and job crafting. Curr Psychol. 2021. doi:10.1007/s12144-021-01658-y

33. Nishimura T, Suzuki T. Basic psychological need satisfaction and frustration in Japan: controlling for the big five personality traits. Japan Psychol Res. 2016;58(4):320-331. doi:10.1111/jpr.12131

34. Cheng B, Zhou X, Guo G, Yang K. Perceived overqualification and cyberloafing: a moderated-mediation model based on equity theory. $J$ Bus Ethics. 2020;164(3):565-577. doi:10.1007/s10551-018-4026-8

35. Mirkovski K, Yin C, Liu L, Yang J. Exploring the contingent effect of community equity on users' intention to share information. Info Syst Front. 2019;21(4):845-860. doi:10.1007/s10796-017-9777-8

36. Kim KH. Cultural influence on creativity: the relationship between Asian culture (Confucianism) and creativity among Korean educators. $J$ Creat Behav. 2009;43(2):73-93. doi:10.1002/j.2162-6057.2009.tb01307.x

37. He R, Zhou M, Liu J, Yang Q. The influence of academic independent directors and Confucianism on carbon information disclosure: evidence from China. Complexity. 2021;2021:6646345. doi:10.1155/2021/6646345

38. Jebran K, Chen S, Ye Y, Wang C. Confucianism and stock price crash risk: evidence from China. North Am J Econ Finance. $2019 ; 50: 100995$. doi:10.1016/j.najef.2019.100995

39. Tang X, Gu Y, Weng R, Ho K. Confucianism and corporate fraud. Int J Emerg Markets. 2021. doi:10.1108/IJOEM-12-2019-1004

40. Zhang J, Liu EY. Confucianism and youth suicide in rural China. Rev Relig Res. 2012;54(1):93-111. doi:10.1007/s13644-011-0027-0

41. Liu L, Fang -C-C. Effects of health-promoting leadership on employee engagement through workplace ostracism, moderated by employability. Int J Manag. 2020;11(10):393-401.

42. Griep Y, Vantilborgh T. Reciprocal effects of psychological contract breach on counterproductive and organizational citizenship behaviors: the role of time. J Vocat Behav. 2018;104:141-153. doi:10.1016/j.jvb.2017.10.013

43. Du X. Does Confucianism reduce minority shareholder expropriation? Evidence from China. J Bus Ethics. 2015;132(4):661-716. doi:10.1007/ s10551-014-2325-2

44. Rousseau DM. Psychological and implied contracts in organizations. Employee Responsib Rights J. 1989;2(2):121-139. doi:10.1007/BF01384942

45. Rousseau D. Psychological Contracts in Organizations: Understanding Written and Unwritten Agreements. London, UK: Sage; 1995.

46. Freese C, Schalk R, Croon M. The impact of organizational changes on psychological contracts: a longitudinal study. Person Rev. 2011;40 (4):404-422. doi:10.1108/00483481111133318

47. Rayton BA, Yalabik ZY. Work engagement, psychological contract breach and job satisfaction. Int J Human Resource Manag. 2014;25 (17):2382-2400. doi:10.1080/09585192.2013.876440

48. Zhang Y, Ren T, Li X. Psychological contract and employee attitudes: the impact of firm ownership and employment type. Chin Manag Stud. 2019;13(1):26-50. doi:10.1108/CMS-06-2017-0171

49. Tsui-hsu tsai T, Jing lin A. Do psychological contract and organizational citizenship behavior affect organizational performance in non-profit organizations? Chin Manag Stud. 2014;8(3):397-417. doi:10.1108/CMS-05-2013-0090

50. Rudolph CW, Katz IM, Lavigne KN, Zacher H. Job crafting: a meta-analysis of relationships with individual differences, job characteristics, and work outcomes. J Vocat Behav. 2017;102:112-138. doi:10.1016/j.jvb.2017.05.008

51. Chang H-T, Hsu H-M, Liou J-W, Tsai C-T. Psychological contracts and innovative behavior: a moderated path analysis of work engagement and job resources. J Appl Soc Psychol. 2013;43(10):2120-2135. doi:10.1111/jasp.12165

52. Lu C-Q, Wang H-J, Lu J-J, Du D-Y, Bakker AB. Does work engagement increase person-job fit? The role of job crafting and job insecurity. $J$ Vocat Behav. 2014;84(2):142-152. doi:10.1016/j.jvb.2013.12.004

53. Ravlin EC, Liao Y, Morrell DL, Au K, Thomas DC. Collectivist orientation and the psychological contract: mediating effects of creditor exchange ideology. J Int Bus Stud. 2012;43(8):772-782. doi:10.1057/jibs.2012.17

54. Kim SH, Laffranchini G, Wagstaff MF, Jeung W. Psychological contract congruence, distributive justice, and commitment. J Manag Psychol. 2017;32(1):45-60. doi:10.1108/JMP-05-2015-0182

55. Lee C, Pillutla M, Law KS. Power-distance, gender and organizational justice. J Manage. 2000;26(4):685-704. doi:10.1177/014920630002600405

56. O'Connor EP, Crowley-Henry M. Exploring the relationship between exclusive talent management, perceived organizational justice and employee engagement: bridging the literature. J Bus Ethics. 2019;156(4):903-917. doi:10.1007/s10551-017-3543-1

57. Niehoff BP, Moorman RH. Justice as a mediator of the relationship between methods of monitoring and organizational citizenship behavior. Acad Manag J. 1993;36(3):527-556.

58. Brislin RW. The wording and translation of research instruments. In: Lonner WJ, Berry JW, editors. Field Methods in Cross-cultural Research Methods. Newbury Park: CA Sage; 1986.

59. Podsakoff PM, MacKenzie SB, Podsakoff NP. Sources of method bias in social science research and recommendations on how to control it. Ann Rev Psychol. 2012;63:539-569. doi:10.1146/annurev-psych-120710-100452 
60. Podsakoff PM, MacKenzie SB, Lee J-Y, Podsakoff NP. Common method biases in behavioral research: a critical review of the literature and recommended remedies. J Appl Psychol. 2003;88(5):879-903. doi:10.1037/0021-9010.88.5.879

61. Mossholder KW, Bennett N, Kemery ER, Wesolowski MA. Relationships between bases of power and work reactions: the mediational role of procedural justice. J Manage. 1998;24(4):533-552. doi:10.1177/014920639802400404

62. Bagozzi RP, Yi Y. On the evaluation of structural equation models. J Acad Market Sci. 1988;16(1):74-94. doi:10.1007/BF02723327

63. Fornell C, Larcker DF. Evaluating structural equation models with unobservable variables and measurement error. J Market Res. 1981;18(1):39-50. doi:10.1177/002224378101800104

64. Davison AC, Hinkley DV. Bootstrap Methods and Their Application. Cambridge: Cambridge university press; 1997.

65. Rogala A, Cieslak R. Positive emotions at work and job crafting: results from two prospective studies. Front Psychol. 2019;10:2786. doi:10.3389/ fpsyg.2019.02786

\section{Publish your work in this journal}

Psychology Research and Behavior Management is an international, peer-reviewed, open access journal focusing on the science of psychology and its application in behavior management to develop improved outcomes in the clinical, educational, sports and business arenas. Specific topics covered in the journal include: Neuroscience, memory and decision making; Behavior modification and management; Clinical applications; Business and sports performance management; Social and developmental studies; Animal studies. The manuscript management system is completely online and includes a very quick and fair peer-review system, which is all easy to use. Visit http://www.dovepress.com/testimonials.php to read real quotes from published authors.

Submit your manuscript here: https://www.dovepress.com/psychology-research-and-behavior-management-journal 